\title{
Strain vessel hypothesis: a viewpoint for linkage of albuminuria and cerebro-cardiovascular risk
}

\author{
Sadayoshi Ito, Tasuku Nagasawa, Michiaki Abe and Takefumi Mori
}

Albuminuria is closely associated with stroke and cardiovascular diseases (CVDs) as well as the salt sensitivity of blood pressure (BP). Although albuminuria may reflect generalized endothelial dysfunction, there may be more specific hemodynamic mechanisms underlying these associations. Cerebral hemorrhage and infarction occur most frequently in the area of small perforating arteries that are exposed to high pressure and that have to maintain strong vascular tone in order to provide large pressure gradients from the parent vessels to the capillaries. Analogous to the perforating arteries are the glomerular afferent arterioles of the juxtamedullary nephrons. Hypertensive vascular damage occurs first and more severely in the juxtamedullary glomeruli. Therefore, albuminuria may be an early sign of vascular damages imposed on 'strain vessels' such as perforating arteries and juxtamedullary afferent arterioles. Coronary circulation also occurs under unique hemodynamic conditions, in which the entire epicardial segments are exposed to very high pressure with little flow during systolic phases. From the evolutionary point of view, we speculate that such circulatory systems in the vital organs are mandatory for survival under the danger of hypoperfusion due to difficult access to salt and water as well as high risks of wound injuries. In addition, albuminuria would indicate an impairment of renal medullary circulation, downstream from the juxtamedullary glomeruli, and therefore an impaired pressure natriuresis, which would lead to salt sensitivity of BP. Our 'strain vessel hypothesis' may explain why hypertension and diabetes, unforeseen in the concept of evolution, preferentially affect vital organs such as the brain, heart and kidney. Hypertension Research (2009) 32, 115-121; doi:10.1038/hr.2008.27; published online 16 January 2009

Keywords: albuminuria; cardiovascular disease; chronic kidney disease; renal injury

\section{INTRODUCTION}

Chronic kidney disease (CKD), defined by reduced glomerular filtration rate $(\mathrm{GFR})\left(<60 \mathrm{ml} \mathrm{min}^{-1}\right)$ and/or the presence of renal damages such as microalbuminuria, is a significant threat for public health in modern societies. ${ }^{1}$ Recent epidemiological studies have shown that $\mathrm{CKD}$ is a significant risk for cardiovascular events independently of classic risk factors such as hypertension, dyslipidemia and diabetes. ${ }^{2-4}$ The mechanisms by which CKD increases the risk of cardiovascular events are currently under intensive investigation. Among the various components of $\mathrm{CKD}$, microalbuminuria is of particular interest, because it is a significant risk factor not only in diabetic and hypertensive subjects but also in the general population. ${ }^{2,5-8}$ Microalbuminuria is also closely associated with the salt sensitivity of blood pressure (BP), and the salt sensitivity is an independent risk factor for cardiovascular diseases (CVDs) even in normotensive subjects. ${ }^{9}$ Studies have now shown that albuminuria even within the normal range is associated with higher incidence and prevalence of stroke and CVDs. ${ }^{10,11}$ However, despite the clear associations with albuminuria and cardiovascular events, the pathophysiological mechanisms underlying these events are largely unknown. Here, we propose 'the strain vessel hypothesis' as a possible mechanism for cerebro-cardio-renal connections. Our hypothesis takes into account the anatomical and functional characteristics of the microvasculature of the vital organs, such as the brain, heart and kidney.

\section{ALBUMINURIA AND CEREBRO-CARDIOVASCULAR RISK}

In 1984, Mogensen reported that microalbuminuria predicted clinical proteinuria and early mortality in type 2 diabetes. ${ }^{12}$ Since then, many cross-sectional and longitudinal studies have shown that albuminuria is closely associated with the prevalence and incidence of CVDs, and is also an adverse prognostic indicator in diabetic and non-diabetic populations. Albuminuria has been shown to cluster with a number of risk factors, including hypertension, dyslipidemia, renal dysfunction, hyperhomocysteinemia and various inflammatory and oxidative stress markers. ${ }^{13,14}$ Even after adjustment of these factors, albuminuria is found to be an independent predictor for adverse cardiovascular events, and this risk increases in a continuous fashion with the degree of albuminuria. ${ }^{11}$ For example, the Multiple Risk Factor Intervention Trial showed that proteinuria is a risk factor for CVD mortality over 10 years of follow-up. ${ }^{15}$ Wada et al. ${ }^{8}$ performed brain magnetic resonance imaging in 651 elderly subjects and found that the level of albuminuria was associated with cerebral small vessel disease, 
independently of other cerebrovascular risk factors such as diabetes, hypertension and dyslipidemia. In the Hypertension Outcome Prevention and Evaluation study, increased levels of albuminuria even within the normal range were found to be associated with higher cardiovascular events in either diabetic or non-diabetic individuals. ${ }^{16}$ In addition, the association between microalbuminuria and CVDs has been shown not only in diabetic and hypertensive populations but also in apparently healthy subjects. ${ }^{5,17}$ Furthermore, recent clinical trials have shown that reduction of albuminuria is significantly related to improved outcomes in albuminuric subjects. ${ }^{2,18,19}$ Thus, the clinical significance of albuminuria is clearly established, and various guidelines for the management of hypertension list albuminuria as a risk factor or a sign of renal damage. Interestingly, the 2007 ESH/ESC guidelines state that the term 'microalbuminuria' may be misleading and also falsely suggests a minor damage. ${ }^{20}$

\section{ALBUMINURIA AND ENDOTHELIAL DYSFUNCTION}

The mechanisms of the association between albuminuria and CVDs are still largely unknown and are a focus of intensive research and debate. ${ }^{21-23}$ It has been suggested that albuminuria not only reflects glomerular damage, but also is a sensitive indicator of generalized endothelial dysfunction and capillary vasculopathy that leads to penetration of atherosclerotic lipoproteins into the arterial walls. ${ }^{24-}$ ${ }^{26}$ Although albuminuria is associated with endothelial dysfunction in systemic circulation, ${ }^{26}$ the mechanism for this association remains unclear. Whether the endothelial dysfunction in general circulation can be deduced from the presence of albuminuria is an issue of considerable debate, because glomerular endothelial cells are quite distinct from those of general circulation. Normally, the endothelial cells of the glomerulus may not be the major barrier for albumin, but the basement membrane and podocytes are the predominant determinant of albumin leakage into the urine. ${ }^{27,28}$ Thus, endothelial dysfunction of the glomerulus alone may not cause albuminuria unless it affects the functions of the basement membrane or podocytes. ${ }^{29,30}$ This issue is particularly pertinent in the absence of systemic hypertension. Why does the presence of albuminuria even within the normal range confer a significant cardiovascular risk in the normotensive and apparently healthy subjects?

\section{NEPHRON HETEROGENEITIES OF HYPERTENSIVE RENAL DAMAGE}

It is well known that hypertension causes renal injury. However, it is not widely recognized that at least in certain types of hypertension considerable heterogeneities exist among different nephron populations. ${ }^{31-34}$ Specifically, tissue injury is most obvious in the juxtamedullary region and outer medulla in spontaneously hypertensive rats (SHRs), ${ }^{31}$ Dahl salt-sensitive hypertensive rats, ${ }^{32}$ renovascular hypertension $^{33}$ and angiotensin II (Ang II)-induced hypertension. ${ }^{34}$ In addition, it has been shown that in SHRs glomerular lesions first appear predominantly in the juxtamedullary nephrons and then extend toward more superficial nephrons. ${ }^{31}$ Such distinct localization of renal injuries and mode of progression may be related to the anatomical and functional heterogeneities of different nephron populations.

Figure 1 illustrates the anatomical relationships of the renal vasculature and tubular segments. The juxtamedullary glomeruli are located deep in the cortex and their afferent arterioles arise from either the initial segment of the interlobular artery or directly from the arcuate artery. In more superficial nephrons, their glomerular afferent arterioles branch off from the more distal segments of the interlobular arteries. Since glomerular capillary pressure is normally maintained at

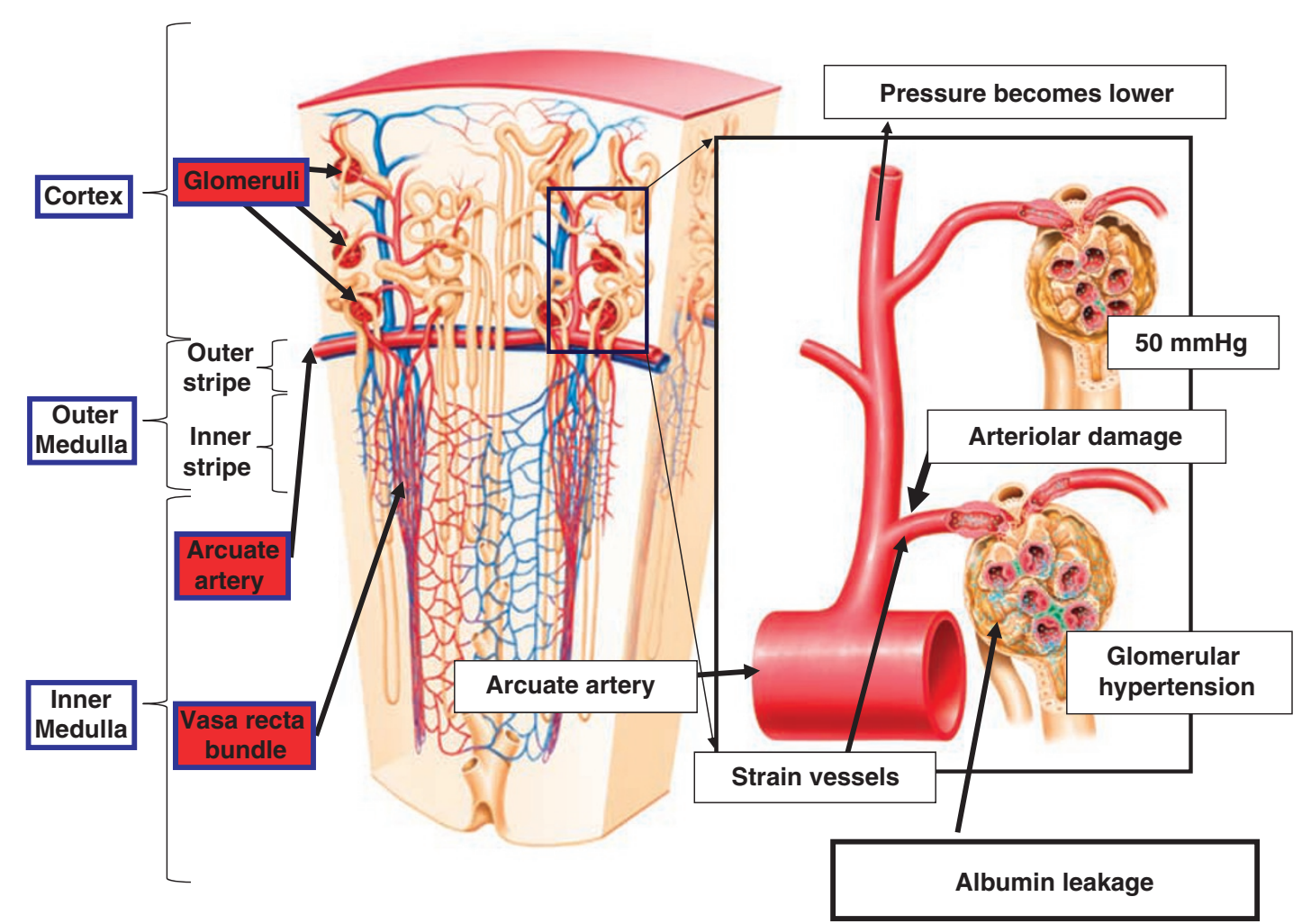

Figure 1 Anatomical structures of the renal vasculatures and the tubular segments. The afferent arteriole of juxtamedullary nephron is the first branch of the interlobular artery. Details are described in the text. 
about $50 \mathrm{~mm} \mathrm{Hg}$ by autoregulation in all nephrons, ${ }^{35}$ the pressure gradient across the afferent arteriole would be greatest in the juxtamedullary nephron. In other words, the juxtamedullary afferent arteriole is exposed to an unusually high pressure as a vessel of its size (about $20 \mu \mathrm{m}$ ), and therefore has to maintain a strong vascular tone in order to provide this large pressure gradient in a short distance between the large arcuate artery, where the pressure is normally about $90 \mathrm{mmHg}$, and the glomerulus. In contrast, in the superficial nephrons, a more gradual pressure reduction occurs along the greater length of the vasculature, including the entire interlobular artery and afferent arterioles. It is of note that the interlobular artery also participates in renal autoregulation, ${ }^{36,37}$ and therefore the feeding pressure of the superficial afferent arteriole is substantially lower than that of the juxtamedullary afferent arteriole. ${ }^{36}$ Thus, the pressure load per unit length of the afferent arteriole is much larger in the juxtamedullary nephrons compared with the more superficial nephrons, owing to which elevations of renal perfusion pressure would impact first and more severely within the walls of the juxtamedullary afferent arteriole. When the afferent arterioles are damaged by hypertension, they lose their autoregulatory ability, ${ }^{38}$ resulting in glomerular hypertension and subsequently glomerular sclerosis.

In addition to anatomical heterogeneities, some differences in the mechanism of autoregulation in the superficial and juxtamedullary afferent arterioles may contribute to the unique localization of renal injuries seen in various hypertensive models. The two major mechanisms of autoregulation are the myogenic response and tubuloglomerular feedback (TGF). ${ }^{39-43}$ The myogenic response is a very fast response, whereas TGF is a rather slower response that requires a time lag between a change in afferent arteriolar pressure and a change in tubular fluid composition at the macula densa. ${ }^{44,45}$ The contribution of TGF to autoregulation has been shown to be much greater in the juxtamedullary nephron than in the superficial nephron. ${ }^{35}$ Thus, when BP changes suddenly, transient changes in glomerular capillary pressure would be greater in the juxtamedullary nephron than in the superficial nephron. Interestingly, it is reported that in SHRs, such transient changes in glomerular capillary pressure of the juxtamedullary nephron are much greater than in normotensive Wistar-Kyoto rats. ${ }^{46}$ In addition, micropuncture studies have shown that only juxtamedullary (but not superficial) glomerular capillary pressure is elevated in SHR as compared with WKY, and this elevation becomes prominent in old SHRs. ${ }^{31}$ Finally, it is reported that uninephrectomy causes selective deep nephron hyperfiltration in SHRs but not in WKY. ${ }^{47}$ These alterations in zonal hemodynamics within the kidney may be able to explain the observation that glomerular sclerosis is seen primarily in the juxtamedullary nephrons in SHR, despite the fact that whole kidney autoregulation is well preserved and the degree of total renal damage is much less than that seen in other hypertensive models, such as in Ang II-induced hypertension and Dahl salt-sensitive hypertensive rats. ${ }^{48-53}$

The study of Mori et al. ${ }^{34}$ in Ang II-induced hypertension gives a strong support to the concept that hypertension itself causes tissue injuries primarily in the juxtamedullary cortex and outer medulla. Using the servo-control method, they kept perfusion pressure to the left kidney at a normotensive level, while inducing systemic hypertension by intravenous infusion of Ang II. As shown in Figure 2a, in the representative histological sections, there were extensive juxtamedullary glomerular and outer medullary tubulointerstitial injuries in the
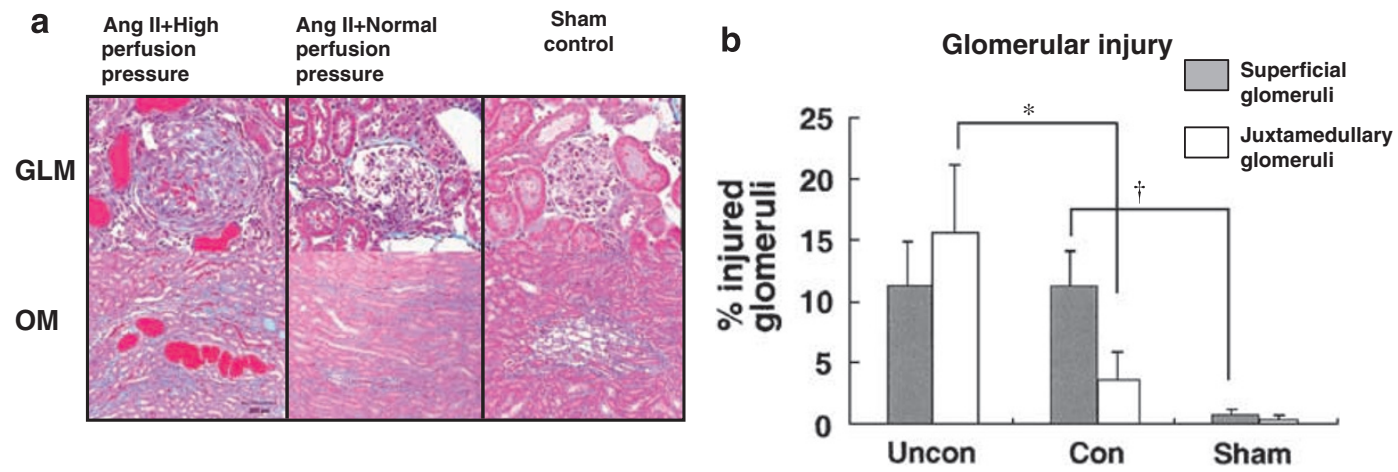

\begin{tabular}{l|c|c} 
C & Pressure & Angiotensin II \\
\hline Superficial & $9 \%$ & $91 \%$ \\
Glomeruli & & \\
Juxtamedullary & $85 \%$ & $15 \%$ \\
Glomeruli & $63-81 \%$ & $19-37 \%$ \\
Interlobular artery & $77 \%$ & $23 \%$ \\
Tubular injury & $59-78 \%$ & $22-41 \%$ \\
Interstitial fibrosis &
\end{tabular}

Figure 2 (a) Renal histology of servo-uncontrolled (Uncon), controlled (Con) and sham (Sam) kidneys. Tissues were stained with Gomori's trichrome staining. Pictures on the top show the juxtamedullary glomeruli. Severe glomerular sclerosis and mesangial proliferation in juxtamedullary glomeruli are observed in the uncontrolled kidney. Pictures at the bottom show the outer medullary region. Tubular necrosis with protein cast and interstitial fibrosis are observed in the outer medullary region of the uncontrolled kidney and to a lesser extent in the controlled kidney. Sham kidneys from the same regions were prepared for comparison. (b) Glomerular injuries of superficial and juxtamedullary glomeruli in BP-uncontrolled, BP-controlled and sham kidneys. Glomerular injury was scored in 50 glomeruli from superficial glomeruli (gray bars) and juxtamedullary glomeruli (white bars). The percentage of glomeruli that exhibited an injury score of 2-4 was plotted (\% injured glomeruli). *Significant $(P<0.05)$ injury protection in controlled kidney compared with uncontrolled kidney. ${ }^{\dagger}$ Significant injury in controlled kidney compared with sham kidney. (c) Percentage of injury attributed to renal perfusion pressure and angiotensin II. Renal injury due to renal perfusion pressure or angiotensin II was estimated by the difference between uncontrolled and controlled, or between controlled and sham kidneys, respectively. Data re-graphed from Mori et al. ${ }^{34}$ 
pressure-uncontrolled right kidney. However, despite the exposure to high Ang II, tissue damages were largely prevented in the pressurecontrolled left kidney. Figure $2 \mathrm{~b}$ summarizes the degree of glomerular injuries in this study. In contrast to the great attenuation of injuries in the juxtamedullary glomeruli in the pressure-controlled kidney, the superficial glomeruli were damaged to a similar extent in both the right and left kidneys. The elevated renal perfusion pressure therefore caused tissue injuries primarily in the juxtamedullary glomeruli and tubulointerstitium of the outer medulla, whereas the Ang II alone resulted in injuries to the superficial nephrons independent of the levels of perfusion pressure (Figure 2c). As hypertension would affect the juxtamedullary nephrons much more strongly than the superficial nephrons as discussed earlier, one would predict that prevention of renal pressure elevation in the Ang II model of hypertension would have greatly reduced injuries of the juxtamedullary nephrons. In addition, there are heterogeneities in the vasoconstrictor actions of Ang II in the superficial and juxtamedullary afferent arterioles. By microperfusing the afferent arteriole, in vitro, we have previously shown that vasoconstriction induced by intraluminal Ang II is much stronger in the superficial than in the juxtamedullary afferent arterioles, with maximal constriction being $70 \%$ and $30 \%$, respectively. ${ }^{54}$ Thus, when a high concentration of Ang II is present in renal circulation, it would constrict the superficial afferent arteriole very strongly, and consequently ischemic damages would be induced irrespective of whether BP is elevated or not.

For the tubulointerstitial injuries of the outer medulla seen in various hypertensive models, ${ }^{32-34}$ several factors would seem to be involved. Blood flow to the renal medulla is supplied by the descending vasa recta, which emanate from the efferent arterioles of the juxtamedullary glomeruli (Figure 1). ${ }^{55}$ In the outer medulla, particularly in the inner stripe, descending vasa recta (containing arterial blood) and ascending vasa recta (containing venous blood) run sideby-side in opposite directions, forming a counter-current circulation. ${ }^{56}$ Oxygen thereby diffuses from the descending to the ascending vasa recta, reducing the oxygen content as blood descends through the vasa recta vessels. ${ }^{56}$ In addition, oxygen consumption is very high in the outer medulla because of the high levels of active ion transport in the thick ascending limbs of the loops of Henle (TALs) and proximal straight tubules, thereby reducing the oxygen content even further in this region. ${ }^{56-61}$ In contrast, oxygen consumption is very small in the inner medulla because there is no active transport by the thin loop of Henle and therefore tissue oxygen tension is well preserved. ${ }^{56}$ Thus, the outer medulla is the anatomical site most susceptible to injuries such as ischemia. ${ }^{62}$ When the juxtamedullary glomeruli are injured by hypertension, the impairment of oxygen delivery downstream from the vasa recta vessels would be expected to result in tubulointerstitial injuries in the outer medulla. Superimposed on these factors, a number of other elements, including neurohormonal factors, ${ }^{56}$ inflammatory pathways, ${ }^{53}$ oxidative stress ${ }^{63,64}$ and tubular transport, ${ }^{65,66}$ are involved in the pathogenesis of the injuries, among which tubulovascular crosstalk is of particular interest. ${ }^{63,64,67,68}$ We have recently shown that an increase in tubular transport at the mTAL enhances superoxide production and reduces nitric oxide synthesis. ${ }^{63-65,67}$ These changes would be transmitted to the neighboring vasa recta and would therefore facilitate vasoconstriction and reduction of medullary blood flow.

\section{ALBUMINURIA AS AN EARLY MARKER OF STRAIN VESSEL INJURIES}

Many diseases and mechanisms have been proposed to cause microalbuminuria. ${ }^{30}$ However, as discussed above, regardless of the pathogenesis of microalbuminuria, the anatomical sites that are injured initially or more severely are the juxtamedullary afferent arterioles and glomeruli. ${ }^{32-34}$ It would be reasonable to expect that in the early stages of hypertension, diabetes or aging, renal injury occurs predominantly in the juxtamedullary nephrons, whereas the majority of other nephrons remain relatively intact. This would be expected to result in only minimal increases of urinary albumin excretion.

From the hemodynamic point of view, the juxtamedullary afferent arterioles are small and short vessels that are exposed to a high pressure and therefore have to maintain a strong vascular tone in order to provide a large pressure gradient in a short distance. ${ }^{69}$ We will refer to these kinds of vessels as 'strain vessels'. Thus, microalbuminuria may be an early marker of vascular damages of strain vessels within the body. Other strain vessels exist most notably in the central nervous system, where many perforating arteries arise directly from large high-pressure arteries, such as anterior, middle or posterior cerebral arteries, and penetrate into the brain tissues (Figure 3). ${ }^{70}$ As in the case of juxtamedullary afferent arterioles, these perforating arteries are exposed to a high pressure and therefore have to maintain large pressure gradients from their parent arteries to brain tissue capillaries. $^{71,72}$ It is well known that the sites of hemorrhage or infarction in the brain are frequently the areas of blood supply governed by these perforating arteries..$^{70,73}$ Thus, 'strain vessel injuries' may explain the link between vascular damage and microalbuminuria in the kidney and cerebral stroke. Indeed we recently observed that in stroke-prone spontaneously hypertensive rats (SHR-SPs) fed a highsalt diet, appearance of significant albuminuria was closely associated with vascular injuries in both the juxtamedullary nephrons and the perforating arteries of middle cerebral arteries, whereas superficial nephrons remained relatively intact (unpublished observations). According to our hypothesis, the relatively weak relationships observed between albuminuria and endothelial dysfunction can be attributed to the endothelial dysfunction of strain vessels preceeding that of the general circulation under various conditions, such as hypertension, diabetes and aging. In addition, the importance of arterial stiffness for the association between cerebro-CVDs and albuminuria may be deduced ${ }^{74}$ from the fact that strain vessels are directly influenced by the hemodynamics of large arteries. Unlike other small vessels in peripheral circulation in which blood flow and pressure are rather constant, the strain vessels are exposed to pulsatile pressure and flow, and therefore the stiffness of large arteries would greatly influence the burden imposed on strain vessels. ${ }^{75,76}$

There may be similar, albeit not the same, hemodynamic conditions existing in the coronary circulations. ${ }^{77}$ It is well known that coronary blood flow depends primarily on diastolic and not on systolic BP: ${ }^{78,79}$ namely, coronary arteries arise directly from the aorta, and during the systolic phase there is little coronary blood flow because intramyocardial vessels are compressed due to myocardial contraction. This creates a unique situation that during the systolic phase the entire epicardial segments of coronary arteries, including small arteries just before their entering the myocardium, are exposed to a very high pressure, because there is little outflow. Studies have shown that coronary arteries (particularly small-sized segments) exhibit myogenic responses, ${ }^{80,81}$ so that when intraluminal pressure is elevated, they would contract strongly in order to maintain vascular integrity. Therefore, although coronary arteries do not provide a pressure gradient, they would still be under high-pressure hemodynamic conditions with a strong vascular tone, which would be similar, though not the same, to those of strain vessels in the kidney and central nervous system.

Our strain vessel hypothesis would also explain the close linkage between hypertensive retinopathy and cerebro-CVDs as reviewed by 

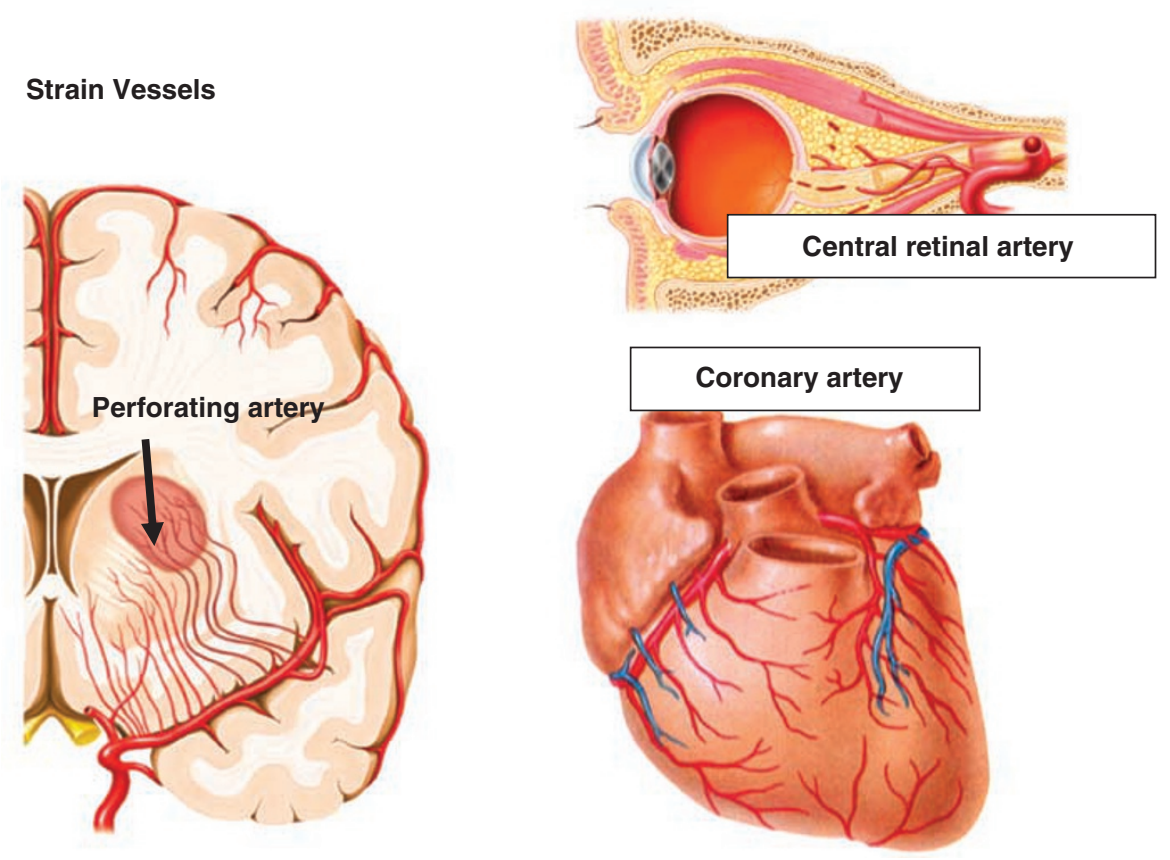

Figure 3 Strain vessels similar to juxtamedullary afferent arteriole within the body. Left panel: perforating arteries in the central nervous system. Top right panel: retinal artery. Bottom right panel: coronary arteries. These are the vessels that are exposed to very high pressure and maintain a high vascular tone (a strain vessel). Microalbuminuria may be an indicator of vascular damages of these strain vessels.

Wong et al. ${ }^{82}$ The retinal artery is derived from the ophthalmic artery, which is the first branch emanating from the high-pressure internal carotid artery. The pressure in the central retinal artery, which can be measured by an ophthalmodynamometer, is about half of the systemic $\mathrm{BP}^{83}$ Therefore, retinal circulation has hemodynamic characteristics similar to those of perforating arteries. Hypertensive retinopathy is a microvascular injury associated with increased BP and has long been an indicator of atherosclerosis. ${ }^{84,85}$ The risk of incident stroke increases by $2-3$-folds in patients with retinopathy. Hypertensive retinopathy is also associated with microalbuminuria, renal dysfunction and left ventricular hypertrophy. ${ }^{86,87}$ Approximately two-thirds of patients with central retinal artery occlusion have high BP and one-fourth are associated with cardiovascular diseases.

\section{ALBUMINURIA AND SALT SENSITIVITY OF BP}

One of the features of microalbuminuria is its close association with the salt sensitivity of $\mathrm{BP},{ }^{9,88}$ and this association is observed even in normotensive subjects. ${ }^{9}$ Salt-sensitive hypertension is characterized by glomerular hypertension, microalbuminuria, ${ }^{89}$ and a higher mortality and morbidity of cardiovascular events. ${ }^{89,90}$ Interestingly, the association between microalbuminuria and salt sensitivity of BP has been shown not only in diabetic or hypertensive populations but also in apparently healthy subjects. ${ }^{9}$

There are many mechanisms involved in the salt sensitivity of BP. When salt is ingested with meals, various neuro-hormonal changes, such as inhibition of the renin-angiotensin system and enhanced production of prostaglandin, would occur and thereby increase GFR and reduce tubular sodium reabsorption. These changes would promote sodium excretion; however, in order to accomplish complete sodium balance, these alone would not be sufficient, and would therefore require the mechanism of pressure natriuresis (Figure 4). ${ }^{91}$ According to our hypothesis, microalbuminuria indicates the existence of damages in juxtamedullary afferent arterioles and glomeruli, and therefore impairments in the downstream medullary circulation. As

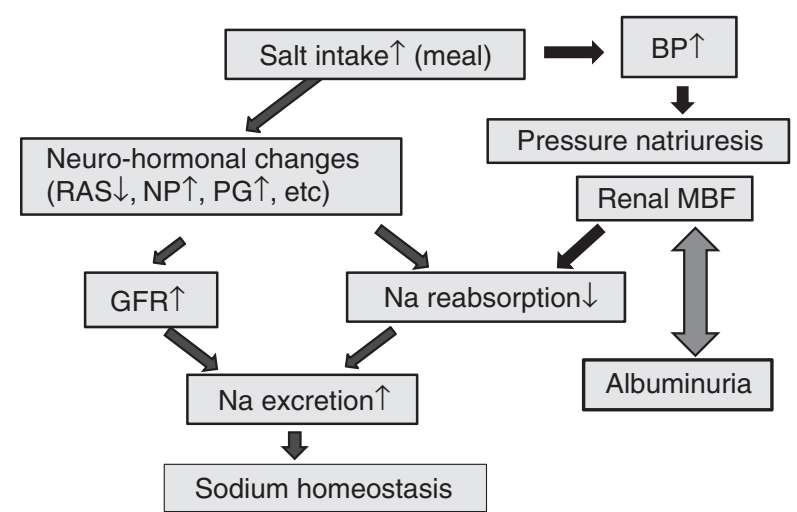

Figure 4 Possible mechanism linking albuminuria and the salt sensitivity of blood pressure (BP). Increase in renal perfusion pressure promotes natriuresis (pressure natriuresis) and participates in the maintenance of homeostasis of sodium balance. Renal medullary blood flow (MBF) plays a crucial role in the mechanism of pressure natriuresis. Medullary blood flow is supplied via the vasa recta, downstream from the juxtamedullary glomerulus. In the phase of albuminuria, juxtamedullary glomeruli are injured, and therefore downstream circulation through the vasa recta is impaired. This in turn causes blunted pressure natriuresis and consequently an enhanced salt-sensitivity of BP. RAS, renin-angiotensin system; NP, natriuretic peptide; PG, prostaglandin; GFR, glomerular filtration rate.

the medullary circulation plays a crucial role in the mechanisms of pressure natriuresis, ${ }^{92,93}$ microalbuminuria may be related to impaired pressure natriuresis, and therefore the salt sensitivity of BP. Thus, our strain vessel hypothesis may explain the close interrelationships among microalbuminuria, the salt sensitivity of BP, and cerebro-cardiovascular mortality and morbidity. It should be noted, however, that other factors, such as the rennin-angiotensin system and insulin sensitivity, also play a role in the salt sensitivity of BP. 


\section{AN EVOLUTIONARY POINT OF VIEW}

Why do we have such vulnerable structures as strain vessels? From the evolutionary point of view, we speculate that perforating arteries, juxtamedullary nephrons, retinal arteries and coronary circulation have important structure-function relationships. All creatures, in their natural environments, were constantly facing the danger of circulatory collapse. Given the generally difficult access to salt and a high risk of wound injuries, hypotension and hypoperfusion of vital organs were the principal challenges with which they had to cope. Therefore, in order to maintain the perfusion of the vital tissues such as the brainstem, it was necessary to develop circulatory systems in which vessels are branched off directly from the large arteries and deliver blood to the tissue. Without sufficient evolutionary time to adapt to the modern diets of the rapidly developed industrialized societies, the organisms were not designed to cope with high salt intake, hypertension and obesity, as reviewed elsewhere. ${ }^{94-97}$ Taken together, the close link between microalbuminuria, salt sensitivity and CVDs may be viewed as inevitable consequences of evolution. In other words, while we, human beings, enjoy the benefits of the many developments brought in by the industrial evolution, we have to keep in mind that our fate is still governed by the natural law of evolution.

\section{PERSPECTIVES}

There may be several mechanisms underlying the link between the albuminuria and CVDs. It is now clear that hypertension, diabetes and renal dysfunction are associated with endothelial dysfunction. Although albuminuria may be associated with endothelial dysfunction in the systemic circulation, it may better reflect the burden imposed on strain vessels such as juxtamedullary afferent arterioles in the kidney, perforating arteries in the central nervous system, retinal arteries and coronary arteries. The strain vessel hypothesis may explain why hypertension and diabetes, unforeseen in the concept of evolution, preferentially affect vital organs such as the brain, heart and kidney.

\section{ACKNOWLEDGEMENTS}

We thank Allen W Cowley, Jr Eberhard Ritz for carefully reviewing the paper and Sumika Muryoi for providing expert secretarial assistance. This work was supported by the Grants-in-Aid for Scientific Research from the Ministry of Education, Culture, Sports, Science and Technology of Japan (No. 17390245, No. 17590181) and the 21st Century COE Program Special Research Grant from the Ministry of Education, Sports and Culture, and research grant for cardiovascular research (13C-5) from the Ministry of Health, Labor and Welfare of Japan.

1 Sarnak MJ, Levey AS, Schoolwerth AC, Coresh J, Culleton B, Hamm LL, McCullough PA, Kasiske BL, Kelepouris E, Klag MJ, Parfrey P, Pfeffer M, Raij L, Spinosa DJ, Wilson PW. American Heart Association Councils on Kidney in Cardiovascular Disease, High Blood Pressure Research, Clinical Cardiology, and Epidemiology and Prevention. Kidney disease as a risk factor for development of cardiovascular disease: a statement from the American Heart Association Councils on Kidney in Cardiovascular Disease, High Blood Pressure Research, Clinical Cardiology, and Epidemiology and Prevention. Hypertension 2003; 42: 1050-1065.

2 Ibsen H, Olsen MH, Wachtell K, Borch-Johnsen K, Lindholm LH, Mogensen CE, Dahlöf B, Snapinn SM, Wan Y, Lyle PA. Does albuminuria predict cardiovascular outcomes on treatment with losartan versus atenolol in patients with diabetes, hypertension, and left ventricular hypertrophy? The LIFE study. Diabetes Care 2006; 29: 595-600.

3 Eijkelkamp WB, Zhang Z, Remuzzi G, Parving HH, Cooper ME, Keane WF, Shahinfar S, Gleim GW, Weir MR, Brenner BM, de Zeeuw D. Albuminuria is a target for renoprotective therapy independent from blood pressure in patients with type 2 diabetic nephropathy: post hoc analysis from the Reduction of Endpoints in NIDDM with the Angiotensin II Antagonist Losartan (RENAAL) trial. J Am Soc Nephrol 2007; 18: 1540-1546.
4 Forman JP, Brenner BM. 'Hypertension' and 'microalbuminuria': the bell tolls for thee. Kidney Int 2006; 69: 22-28.

5 Hillege HL, Fidler V, Diercks GF, van Gilst WH, de Zeeuw D, van Veldhuisen DJ, Gans RO, Janssen WM, Grobbee DE, de Jong PE. Prevention of Renal and Vascular End Stage Disease (PREVEND) Study Group. Urinary albumin excretion predicts cardiovascular and noncardiovascular mortality in general population. Circulation 2002; 106: 1777-1782.

6 Yuyun MF, Khaw KT, Luben R, Welch A, Bingham S, Day NE, Wareham NJ. Microalbuminuria and stroke in a British population: the European Prospective Investigation into Cancer in Norfolk (EPIC-Norfolk) population study. J Intern Med 2004; 255: 247-256

7 Ravera M, Ratto E, Vettoretti S, Viazzi F, Leoncini G, Parodi D, Tomolillo C, Del Sette M, Maviglio N, Deferrari G, Pontremoli R. Microalbuminuria and subclinical cerebrovascular damage in essential hypertension. J Nephrol 2002; 15: 519-524.

8 Wada M, Nagasawa H, Kurita K, Koyama S, Arawaka S, Kawanami T, Tajima K, Daimon $M$, Kato T. Microalbuminuria is a risk factor for cerebral small vessel disease in community-based elderly subjects. J Neurol Sci 2007; 255: 27-34.

9 Cubeddu LX, Hoffmann IS, Aponte LM, Nuñez-Bogesits R, Medina-Suniaga H, Roa M, Garcia RS. Role of salt sensitivity, blood pressure, and hyperinsulinemia in determining high upper normal levels of urinary albumin excretion in a healthy adult population. Am J Hypertens 2003; 16: 343-349.

10 Klausen KP, Scharling H, Jensen JS. Very low level of microalbuminuria is associated with increased risk of death in subjects with cardiovascular or cerebrovascular diseases. J Intern Med 2006; 260: 231-237.

11 Gerstein HC, Mann JF, Yi Q, Zinman B, Dinneen SF, Hoogwerf B, Hallé JP, Young J, Rashkow A, Joyce C, Nawaz S, Yusuf S. HOPE Study Investigators. Albuminuria and risk of cardiovascular events, death, and heart failure in diabetic and nondiabetic individuals. JAMA 2001; 286: 421-426.

12 Mogensen CE. Microalbuminuria predicts clinical proteinuria and early mortality in maturity-onset diabetes. N Engl J Med 1984; 310: 356-360.

13 Fliser D, Buchholz K, Haller H. EUropean Trial on Olmesartan and Pravastatin in Inflammation and Atherosclerosis (EUTOPIA) Investigators: antiinflammatory effects of angiotensin II subtype 1 receptor blockade in hypertensive patients with microinflammation. Circulation 2004; 110: 1103-1107.

14 Ogawa S, Mori T, Nako K, Kato T, Takeuchi K, Ito S. Angiotensin II type 1 receptor blockers reduce urinary oxidative stress markers in hypertensive diabetic nephropathy. Hypertension 2006; 47: 699-705.

15 Grimm Jr RH, Svendsen KH, Kasiske B, Keane WF, Wahi MM. Proteinuria is a risk factor for mortality over 10 years of follow-up. MRFIT Research Group. Multiple Risk Factor Intervention Trial. Kidney Int 1997; 63: S10-S14.

16 Gerstein HC, Mann JF, Pogue J, Dinneen SF, Hallé JP, Hoogwerf B, Joyce C, Rashkow A, Young J, Zinman B, Yusuf S. Prevalence and determinants of microalbuminuria in highrisk diabetic and nondiabetic patients in the Heart Outcomes Prevention Evaluation Study. The HOPE Study Investigators. Diabetes Care 2000; 23: B35-B39.

17 Hillege HL, Janssen WM, Bak AA, Diercks GF, Grobbee DE, Crijns HJ, Van Gilst WH, De Zeeuw D, De Jong PE, Prevend Study Group. Microalbuminuria is common, also in a nondiabetic, nonhypertensive population, and an independent indicator of cardiovascular risk factors and cardiovascular morbidity. J Intern Med 2001; 249: 519-526.

18 de Zeeuw D, Remuzzi G, Parving HH, Keane WF, Zhang Z, Shahinfar S, Snapinn S, Cooper ME, Mitch WE, Brenner BM. Albuminuria, a therapeutic target for cardiovascular protection in type 2 diabetic patients with nephropathy. Circulation 2004; 110: 921-927.

19 Asselbergs FW, Diercks GF, Hillege HL, van Boven AJ, Janssen WM, Voors AA, de Zeeuw D, de Jong PE, van Veldhuisen DJ, van Gilst WH. Effects of fosinopril and pravastatin on cardiovascular events in subjects with microalbuminuria. Circulation 2004; 110: 2809-2816.

20 Mancia G, De Backer G, Dominiczak A, Cifkova R, Fagard R, Germano G, Grassi G, Heagerty AM, Kjeldsen SE, Laurent S, Narkiewicz K, Ruilope L, Rynkiewicz A, Schmieder RE, Boudier HA, Zanchetti A. ESH-ESC Task Force on the Management of Arterial Hypertension. 2007 ESH-ESC Practice Guidelines for the Management of Arterial Hypertension: ESH-ESC Task Force on the Management of Arterial Hypertension. J Hypertens 2007; 25: 1751-1762.

21 Satchell SC, Tooke JE. What is the mechanism of microalbuminuria in diabetes: a role for the glomerular endothelium? Diabetologia 2008; 51: 714-725.

22 Nosadini R, Velussi M, Brocco E, Brocco E, Abaterusso C, Piarulli F, Morgia G, Satta A, Faedda R, Abhyankar A, Luthman H, Tonolo G. Altered transcapillary escape of albumin and microalbuminuria reflects two different pathogenetic mechanisms. Diabetes 2005; 54: 228-233.

23 de Zeeuw D, Parving $\mathrm{HH}$, Henning RH. Microalbuminuria as an early marker for cardiovascular disease. J Am Soc Nephrol 2006; 17: 2100-2105.

24 Stehouwer CD, Nauta JJ, Zeldenrust GC, Hackeng WH, Donker AJ, den Ottolander GJ. Urinary albumin excretion, cardiovascular disease, and endothelial dysfunction in noninsulin-dependent diabetes mellitus. Lancet 1992; 340: 319-323.

25 Stehouwer CD, Smulders YM. Microalbuminuria and risk for cardiovascular disease: analysis of potential mechanisms. J Am Soc Nephrol 2006; 17: 2106-2111.

26 Malik AR, Sultan S, Turner ST, Kullo IJ. Urinary albumin excretion is associated with impaired flow- and nitroglycerin-mediated brachial artery dilatation in hypertensive adults. J Hum Hypertens 2007; 21: 231-238.

27 Kerjaschki D. Dysfunctions of cell biological mechanisms of visceral epithelial cell (podocytes) in glomerular diseases. Kidney Int 1994; 45: 300-313.

28 Pavenstadt H, Kriz W, Kretzler M. Cell biology of the glomerular podocyte. Physiol Rev 2003; 83: 253-307. 
29 Bianchi S, Bigazzi R, Campese VM. Microalbuminuria in essential hypertension: significance, pathophysiology, and therapeutic implications. Am J Kidney Dis 1999; 34: 973-995.

30 Satchell SC, Tooke JE. What is the mechanism of microalbuminuria in diabetes: a role for the glomerular endothelium? Diabetologia 2008; 51: 714-725.

31 Iversen BM, Amann K, Kvam FI, Wang X, Ofstad J. Increased glomerular capillary pressure and size mediate glomerulosclerosis in SHR juxtamedullary cortex. $\mathrm{Am} \mathrm{J}$ Physiol 1998; 274: F365-F373.

32 Johnson RJ, Gordon KL, Giachelli C, Kurth T, Skelton MM, Cowley Jr AW. Tubulointerstitial injury and loss of nitric oxide synthases parallel the development of hypertension in the Dahl-SS rat. J Hypertens 2000; 18: 1497-1505.

33 Eng E, Veniant M, Floege J, Ingerle J, Alpers CE, Menard J, Clozel JP, Johnson RJ. Renal proliferative and phenotypic changes in rats with two-kidney, one-clip Goldblatt hypertension. Am J Hypertens 1994; 7: 177-185.

34 Mori T, Cowley Jr AW. Role of pressure in angiotensin II-induced renal injury: chronic servo-control of renal perfusion pressure in rats. Hypertension 2004; 43: 752-759.

35 Ericson AC, Sjöquist M, Ulfendahl HR. Heterogeneity in regulation of glomerular function. Acta Physiol Scand 1982; 114: 203-209.

36 Heyeraas KJ, Aukland K. Interlobular arterial resistance: influence of renal arterial pressure and angiotensin II. Kidney Int 1987; 31: 1291-1298.

37 Takenaka T, Suzuki H, Okada H, Hayashi K, Ozawa Y, Saruta T. Biophysical signals underlying myogenic responses in rat interlobular artery. Hypertension 1998; 32: 1060-1065.

38 Inscho EW, Cook AK, Murzynowski JB, Imig JD. Elevated arterial pressure impairs autoregulation independently of AT(1) receptor activation. J Hypertens 2004; 22: $811-818$.

39 Steinhausen M, Endlich K, Weigman DL. Glomerular blood flow. Kidney Int 1990; 38 739.

40 Navar LG. Renal autoregulation: perspective from whole kidney and single nephron studies. Am J Physiol 1977; 233: 366

41 Vallon V, Schnermann J. Tubuloglomerular feedback. Methods Mol Med 2003; 86: 429-441.

42 Thomson SC, Blantz RC. Glomerulotubular balance, tubuloglomerular feedback, and salt homeostasis. J Am Soc Nephrol 2008; 19: 2272-2275.

43 Schnermann J, Briggs JP. Tubuloglomerular feedback: mechanistic insights from genemanipulated mice. Kidney Int 2008; 74: 418-426.

44 Schnermann J, Bridge JP, Weber PC. Tubuloglomerular feedback, prostaglandins, and angiotensin in the autoregulation of glomerular filtration rate. Kidney Int 1984; 25 : 53-64.

45 Cupples WA. Interactions contributing to kidney blood flow autoregulation. Curr Opin Nephrol Hypertens 2007; 16: 39-45.

46 Roald $A B$, Ofstad J, Iversen BM. Attenuated buffering of renal perfusion pressure variation in juxtamedullary cortex in SHR. Am J Physiol Renal Physiol 2002; 282: 506-511.

47 Bank N, Alterman L, Aynedjian HS. Selective deep nephron hyperfiltration in uninephrectomized spontaneously hypertensive rats. Kidney Int 1983; 24: 185-191.

48 Iversen BM, Amann K, Kvam FI, Wang X, Ofstad J. Glomerular capillary pressure and size mediate glomerulosclerosis in SHR juxtamedullary cortex. Am J Physiol 1998; 274: 365-373.

49 Takenaka T, Forster H, De Micheli A, Epstein M. Impaired myogenic responsiveness of renal microvessels in Dahl salt-sensitive rats. Circ Res 1992; 71: 471-480.

50 Hayashi K, Epstein M. Saruta T. Altered myogenic responsiveness of the renal microvasculature in experimental hypertension. J Hypertens 1996; 14: 1387-1401.

51 Carmines PK, Morrison TK, Navar LG. Angiotensin II effects on microvascular diameters of in vitro blood-perfused juxtamedullary nephrons. Am J Physiol 1986; 251: F610-F618.

52 Ichihara A, Imig JD, Inscho EW, Navar LG. Nitric oxide-angiotensin II influences on renal microcirculation in angiotensin II-induced hypertension. Hypertension 1998; $\mathbf{3 1}$ 1255-1260.

53 Mori T, Polichnowski A, Glocka P, Kaldunski M, Ohsaki Y, Liang M, Cowley Jr AW. High perfusion pressure accelerates renal injury in salt-sensitive hypertension. J Am Soc Nephrol 2008; 19: 1472-1482.

54 Ito S, Amin J, Ren Y, Arima S, Abe K, Carretero OA. Heterogeneity of angiotensin action in renal circulation. Kidney Int 1997; 63: S128-S131.

55 Bankir L, Kaissling B, de Rouffignac C, Kriz W. The vascular organization of the kidney of Psammomys obesus. Anat Embryol (Berl) 1979; 155: 149-160.

56 Cowley Jr AW, Mori T, Mattson D, Zou AP. Role of renal NO production in the regulation of medullary blood flow. Am J Physiol Regul Integr Comp Physiol 2003; 284: R1355-R1369.

57 Ostensen J, Stokke ES. Energy requirement of sodium reabsorption in the thick ascending limb of Henle's loop in the dog kidney: effects of bumetanide and ouabain. Acta Physiol Scand 1996; 157: 275-281.

58 Blantz RC, Weir M. Are the oxygen costs of kidney function highly regulated? Curr Opin Nephrol Hypertens 2004; 13: 67-71.

$59 \mathrm{Kiil}$ F, Sejersted OM. Analysis of energy metabolism and mechanism of loop diuretics in the thick ascending limb of Henle's loop in dog kidneys. Acta Physiol Scand 2003; 178: 73-82.

60 Ostensen J, Stokke ES, Hartmann A, Wensell K, Kiil F. Low oxygen cost of carbonic anhydrase-dependent sodium reabsorption in the dog kidney. Acta Physiol Scand 1989; 137: 189-198.

61 Thurau K. Renal Na reabsorption and $\mathrm{O} 2$ uptake in dogs during hypoxia and hydrochlorothiazide infusion. Proc Soc Exp Biol Med 1961; 106: 714-717.
62 Goldfarb M, Abassi Z, Rosen S, Shina A, Brezis M, Heyman SN. Compensated heart failure predisposes to outer medullary tubular injury: studies in rats. Kidney Int 2001; 60: 607-613.

63 Mori T, Cowley AW. Angiotensin II-NAD(P)H oxidase-stimulated superoxide modifies tubulovascular nitric oxide cross-talk in renal outer medulla. Hypertension 2003; 42: 588-593.

64 Mori T, O'Connor PM, Abe M, Cowley Jr AW. Enhanced superoxide production in renal outer medulla of Dahl salt-sensitive rats reduces nitric oxide tubular-vascular cross-talk. Hypertension 2007; 49: 1336-1341.

65 Abe M, O'Connor P, Kaldunski M, Liang M, Roman RJ, Cowley Jr AW. Effect of sodium delivery on superoxide and nitric oxide in the medullary thick ascending limb. $A m ~ J$ Physiol Renal Physiol 2006; 291: 350-357.

66 Mori T, Cowley Jr AW. Renal oxidative stress in medullary thick ascending limbs produced by elevated $\mathrm{NaCl}$ and glucose. Hypertension 2004; 43: 341-346.

67 Mori T, Cowley Jr AW, Ito S. Molecular mechanisms and therapeutic strategies of chronic renal injury: physiological role of angiotensin II-induced oxidative stress in renal medulla. J Pharmacol Sci 2006; 100: 2-8.

68 Dickhout JG, Mori T, Cowley Jr AW. Tubulovascular nitric oxide crosstalk: buffering of angiotensin II-induced medullary vasoconstriction. Circ Res 2002; 91: 487-493.

69 Azar S, Tobian L, Johnson MA. Glomerular, efferent arteriolar, peritubular capillary, and tubular pressures in hypertension. Am J Physiol 1974; 227: 1045-1050.

70 Greenberg SM. Small vessel, big problem. N Engl J Med 2006; 354: 1451-1457.

71 Mohr JP. Progress in cerebrovascular disease. Lacunes. Stroke 1982; 13: 3-10.

72 Auer RN, Sutherland GR. Primary intracerebral hemorrhage: pathophysiology. Can J Neurol Sci 2005; 32: S3-S12.

73 Dubas F. Small vessel pathology and cerebral hemorrhage. J Neuroradiol 2003; 30: 298-302.

74 Hashimoto J, Aikawa T, Imai Y. Large artery stiffening as a link between cerebral lacunar infarction and renal albuminuria. Am J Hypertens 2008; 21: 1304-1309.

75 O'Rourke MF, Safar ME. Between aortic stiffening and microvascular disease in brain and kidney: cause and logic of therapy. Hypertension 2005; 46: 200-204.

76 Struijker Boudier HA, Cohuet GM, Baumann M, Safar ME. Heart, macrocirculation and microcirculation in hypertension: a unifying hypothesis. J Hypertens Supp/ 2003; 21: S19-S23.

77 Camici PG, Crea F. Microvascular dysfunction. N Eng/ J Med 2007; 356: 830-840.

78 Porter WT. The influence of the heart-beat on the flow through the walls of the heart. Am J Physiol 1898; 1: 145-163.

79 Gregg DE. Coronary Circulation in Health and Disease. Lea \& Febiger: Philadelphia, 1950.

80 Cornelissen AJ, Dankelman J, VanBavel E, Stassen HG, Spaan JA. Myogenic reactivity and resistance distribution in the coronary arterial tree: a model study. Am J Physiol Heart Circ Physiol 2000; 278: H1490-H1499.

81 Huang A, Sun D, Yan C, Falck JR, Kaley G. Contribution of 20-HETE to augmented myogenic constriction in coronary arteries of endothelial NO synthase knockout mice. Hypertension 2005; 46: 607-613.

82 Wong TY, Mitchell P. The eye in hypertension. Lancet 2007; 369: 425-435.

83 Weinberger J. Clinical applications of noninvasive carotid artery testing. J Am Coll Cardiol 1985; 5: 137-148.

84 Grosso A, Veglio F, Porta M, Grignolo FM, Wong TY. Hypertensive retinopathy revisited: some answers, more questions. Br J Ophthalmol 2005; 89: 1646-1654.

85 Wong TY, Mitchell P. Hypertensive retinopathy. N Engl J Med 2004; 351: 2310-2317.

86 Shigematsu Y, Hamada M, Ohtsuka T, Hashida H, Ikeda S, Kuwahara T, Hara Y, Kodama K, Hiwada K. Left ventricular geometry as an independent predictor for extracardiac target organ damage in essential hypertension. Am J Hypertens 1998; 11: 1171-1177

87 Cuspidi C, Meani S, Salerno M, Fusi V, Severgnini B, Valerio C, Catini E, Esposito A, Magrini $F$, Zanchetti A. Microvascular changes and target organ damage in untreated essential hypertensives. J Hypertens 2004; 22: 2095-2102.

88 Nesoviæ M, Stojanoviæ M, Nesoviæ MM, Ciriæ J, Zarkoviæ M. Microalbuminuria is associated with salt sensitivity in hypertensive patients. J Hum Hypertens 1996; 10: 573-576.

89 Campese VM. Salt sensitivity in hypertension. Renal and cardiovascular implications. Hypertension 1994; 23: 531-550.

90 Weinberger MH, Fineberg NS, Fineberg SE, Weinberger M. Salt sensitivity, pulse pressure, and death in normal and hypertensive humans. Hypertension 2001; 37: 429-432.

91 Guyton AC, Coleman TG, Cowley Jr AV, Scheel KW, Manning Jr RD, Norman Jr RA. Arterial pressure regulation. Overriding dominance of the kidneys in long-term regulation and in hypertension. Am J Med 1972; 52: 584-594.

92 Cowley Jr AW. Long-term control of arterial blood pressure. Physiol Rev 1992; 72. 231-300.

93 Cowley Jr AW. Role of the renal medulla in volume and arterial pressure regulation. Am J Physiol 1997; 273: R1-R15.

94 Young JH. Evolution of blood pressure regulation in humans. Curr Hypertens Rep 2007; 9: 13-18.

95 Kurokawa K. Kidney, salt, and hypertension: how and why. Kidney Int Supp/ 1996; 55: S46-S51.

96 Tobian L. Protecting arteries against hypertensive injury. Clin Exp Hypertens 1992; 14: 35-43.

97 Lee PY, Yun AJ, Bazar KA. Acute coronary syndromes and heart failure may reflect maladaptations of trauma physiology that was shaped during pre-modern evolution. Med Hypotheses 2004; 62: 861-867. 